\title{
Casas com asas: precisam-se
}

\section{Sebastiana Fadda}

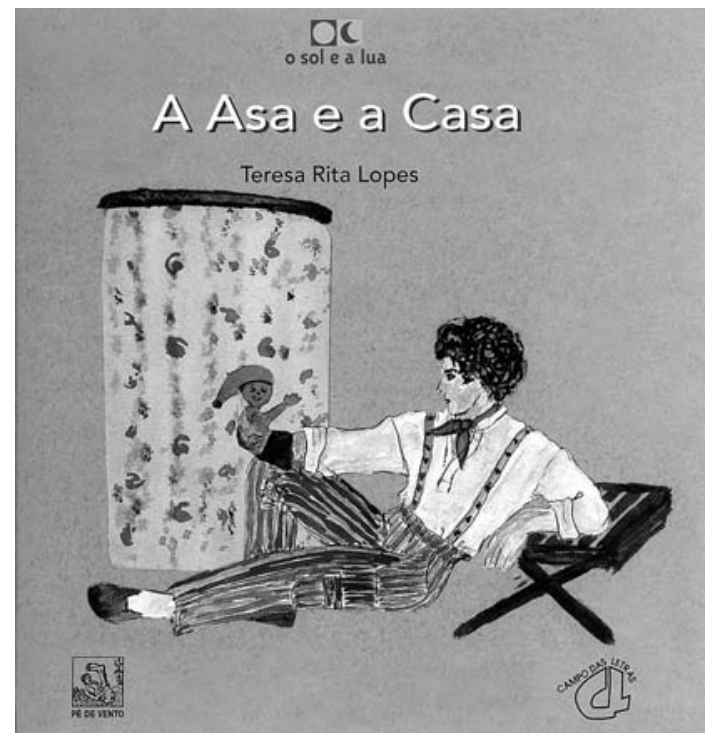

Teresa Rita Lopes partilha com Fiama Hasse Pais Brandão o título de decana das dramaturgas portuguesas actuais. Ambas poetisas e com uma longa experiência ligada ao palco, compõem, juntamente com colegas ligadas a outros géneros ou pertencentes a outras gerações, um importante grupo de autoras que tem vindo a protagonizar uma cena antes dominada quase exclusivamente pela presença masculina. As novas contribuições para o teatro, em termos de criação original ou de adaptações a partir de obras não teatrais, vêm de escritoras ligadas principalmente à narrativa (com destaque para Augustina Bessa Luís, Maria Velho da Costa, Eduarda Dionísio, Hélia Correia, Luisa Costa Gomes e Lídia Jorge), ou de actrizes e encenadoras que mais ou menos pontualmente se dedicam à (re)escrita dramatúrgica (Maria do Céu Ricardo, Isabel Medina, Graça P. Corrêa, Regina Guimarães, Lúcia Sigalho, Mónica Calle e Silvina Pereira, entre outras).

Exemplarmente significativo pela sua coerência e dedicação, particular atenção e apreço merece o percurso de Teresa Rita Lopes. Desde finais dos anos 50, quando era uma jovem estudante universitária, a autora faz da investigação e da escrita - nas modalidades do ensaio, da poesia, do teatro e da narrativa - uma prática de militância civica. Em teatro, contudo, de início, desempenhou as tarefas mais dispares, fazendo parte do Grupo de Teatro da Faculdade de Letras dirigido por Fernando Amado e do Grupo Ribalta,

\author{
Teresa Rita Lopes, A asa e a casa, Porto, Campo das Letras \\ e Teatro Pé de Vento, Colecção 0 Sol e a Lua, 2004, \\ $45 \mathrm{pp}$.
}

até fundar o Grupo de Teatro da Voz do Operário. Peças hoje esquecidas foram premiadas e encenadas por homens que vieram a ocupar um lugar ao sol no panorama do teatro português: Dez contos de reis (1959) recebeu um prémio televisivo e foi encenada por Artur Ramos, tendo entre os intérpretes Armando Cortês, Canto e Castro e Teresa Mota; Uma consciência em paz (1960) foi antes premiada em Jogos Florais universitários, a seguir levada à cena por Rogério Paulo e louvada por Urbano Tavares Rodrigues nas páginas do Diário de Lisboa; A carruagem reservada (1960) marca o encerramento desta fase.'

Uma nova fase, conotada por uma escrita e por temas em que a autora se reconhece ainda hoje, é inaugurada por Três fósforos (1961), censurada três semanas antes da estreia, quando se encontrava em ensaios no Teatro Nacional D. Maria II, integrada no ciclo Teatro de Novos para Novos com encenação de Artur Ramos. A peça não conseguiu ter visibilidade devido à sua não transformação em espectáculo. Sendo a censura prévia mais vigilante relativamente aos espectáculos do que aos textos, chegou a ser publicada no ano seguinte. A partir dai e até hoje, a bibliografia de teatro de Teresa Rita Lopes conta com 17 peças (havendo porém um díptico que a autora considera como uma peça única, mas já disjunto para a cena): Três fósforos(1961), Os pássaros também (1961), Encomendação de João Calafate (1962), O grande reizinho da Pigmilândia (1966), As barbas de Sua Senhoria (1966-67), Sopinhas de mel (início dos anos 70), Díptico: 0 amor sem tréguas: a) Rimance da mal maridada (início dos anos 70) e b) 0 amor sem cara (1993), 0 teatro do Ser (1985), Andando andando (1987), Pessoa e Borges: As tranquilas aventuras do diálogo (1987), 0 privilégio dos caminhos (1988), A proibida azul distância (1991), Pessoa normalizado para uso da CEE (1992), A asa e a casa (1995), Esse tal Alguém (2001), A biblioteca de Campos (2003). Dessas 17 peças apenas 5 têm ficado inéditas, encontrandose todavia em preparação o livro Teatro reunido, que as reagrupará todas numa publicação da Imprensa NacionalCasa da Moeda.

A produção lopesiana apresenta uma grande variedade de temas e registos, com reincidência da matéria pessoana (dispersa em toda a obra e especialmente concentrada em cinco peças), do teatro popular (cuja ascendência é imputável ao Romanceiro de tradição ibérica, bem como a uma das vertentes do teatro vicentino e ao teatro de cordel), do teatro de intervenção (expresso pela metáfora poética, pela farsa satírica ou pelos ecos da tragédia clássica), do teatro
${ }^{1}$ Estas informações são retiradas do texto de autoria de Teresa Rita Lopes, Meu trato com o teatro, já publicadas na revista do Grupo de Teatro Gato de Santo André, Essas páginas de memórias, gentilmente cedidas em cópia pela autora, irão ser integradas in Teresa Rita Lopes, Teatro reunido, Imprensa Nacional-Casa da Moeda, Colecção de Autores Portugueses, no prelo. dirigido por Mário Primo. 
intimista (que foca os conflitos e as tensões dicotómicas que afligem o casal, bem como os desentendimentos gerados pelo uso do mesmo código mas com sistemas referenciais antagónicos).

Apesar de recém-editada, $A$ asa e a casa foi redigida em 1995 e teve a sua estreia absoluta no mesmo ano em Paris, no Centro Cultural Português da Fundação Calouste Gulbenkian. La maison et l'oiseau, com tradução ainda hoje inédita de Gérard Brignol, foi apresentada sob a forma de leitura dramatizada, dirigida por Emmanuel Mota-Demarcy. É este um dos casos pouco frequentes em que a montagem de uma peça portuguesa antecede a sua edição; mais raro ainda pelo facto de uma estreia no estrangeiro anteceder a nacional, que se deu a 4 de Julho de 2003 no Teatro da Vilarinha do Porto pelo Teatro Pé de Vento, com encenação de João Luiz. 0 espectáculo, reposto para o público portuense em 2004, de 12 de Junho a 25 de Julho, foi apresentado no dia 21 de Março em Lisboa, no Centro Cultural de Belém, integrado na Festa da Primavera. Nessa data a Editora Campo das Letras, em colaboração com o Teatro Pé de Vento, procedeu ao lançamento do livro, inserido numa colecção (O Sol e a Lua) destinada à infância e à juventude. Trata-se do terceiro título de Teresa Rita Lopes acolhido por essa editora, tendo sido precedido por Andando andando (1999, também na Colecção 0 Sol e a Lua) e Esse tal Alguém (2001, Colecção Campo da Palavra, obra distinguida com o Grande Prémio de Teatro da Associação Portuguesa de Escritores / Ministério da Cultura 2001).

Convém esclarecer, no respeito da vontade da autora e utilizando as suas palavras, que ela anseia "por uma forma de teatro rebelde a qualquer rótulo que o destine a pequenos e grandes, novos ou velhos, ricos ou pobres, homens ou mulheres, doutores ou analfabetos". Em relação directa com estas afirmações, as opções da dramaturga parecem convergir numa estratégia programática sustentada por valores éticos e estéticos bem definidos. Os seus pontos imprescindiveis seriam: a abolição dos géneros e das hierarquias a nível literário, bem como a recusa de limites de natureza anagráfica, sexual, cultural e económica a nivel de público alvo.

Assim sendo, A asa e a casa assume-se como teatro para toda a gente. Aparenta ser destinado à juventude, mas o tratamento do tema desmente-o. Se, por hipótese, se pensar na presença exclusiva de um público adulto, os recursos formais instigam perplexidades fundamentadas acerca do contrário. Se surgir a suspeita de ser um texto simples e que simplifica o enredo e o conflito, uma leitura menos superficial mostra as suas duas grandes linhas de força: a concentração dos sentidos e a articulação da arquitectura cénico-linguistica.

Pela concentração dos sentidos, o enredo desenvolve agora... sempre digo:", in $A$ asa e a casa, Porto, Campo das Letras e Teatro Pé de Vento, Colecção 0 Sol e a Lua, 2004, p. 3. os conflitos da relação homem-mulher, desde a sedução à aceitação recíproca. Os símbolos eleitos para representar as polaridades masculina e feminina são, respectivamente, a asa e a casa, tal como o próprio título aponta. A asa remete para o desejo duma liberdade que tenha como único limite o espaço inteiro (é esta uma outra metáfora para indicar a livre e total expressão e deambulação do espírito). A casa aponta para a necessidade de se possuir um centro fixo, um ninho protector e estável para onde fazer retorno (reenviando para o instinto telúrico e material de sobrevivência e conservação da espécie ).

$\mathrm{Na}$ estruturação duma arquitectura cénico-linguística articulada, concorrem elementos tão vários como o tom efabulatório da narração (como se de uma fábula com moral final se tratasse), a inserção das quadras populares (a poesia enquanto bálsamo do sentir e sal da comunicação) e a intervenção das marionetas (associadas à reivindicação de momentos lúdicos e à recuperação fugaz da infância perdida). Pela via erudita, do processo de despojamento voluntário e premeditado, sobram as grandes tradições literárias ditas "populares", sobressaindo as virtudes da interacção imediata entre palco e plateia, rejeitando-se os artificios inibidores dessa função.

A autora manipula assim as suas personagens reiterando aquelas soluções éticas e estéticas que Ihe parecem mais convenientes. Todavia, indiferente à moral comum e às tendências da moda, ela faz apelo ao bom senso e ao bom gosto, à reflexão e à critica, a uma atitude construtiva e participativa perante a realidade. Assim, neste caso concreto, a sugestão para o apaziguamento do conflito é a negociação de um compromisso em que as duas partes em causa abdiquem do egoísmo que impede o encontro. Quanto à proposta estética, apesar de predominar o cunho popular, repudia qualquer acento populista, nunca cedendo à tentação de piscar o olho ao espectador para cativar a sua benevolência e adesão.

Se a Campo das Letras continua a desafiar as leis do mercado publicando teatro e confirmando uma linha editorial culturalmente significativa, com A asa e a casa Teresa Rita Lopes acrescenta mais uma pedra ao mosaico teatral que vem construindo há mais de quatro décadas, reforçando a sua unidade interna pela reiteração dos seus temas predilectos e das respectivas variações, bem como do encontro renovado e renovável com a tradição peninsular. 